\title{
Военно-политическое сотрудничество США и Германии в 40-е годы XX в. - первые десятилетия XXI в.
}

\author{
Ю.В. Родович \\ Тульский государственный педагогический университет им. Л.Н. Толстого, \\ Россия, 300026, г. Тула, просп. Ленина, 125 \\ E-mail: tgpu@tula.net
}

\begin{abstract}
Аннотация. В статье рассматривается история военно-политического сотрудничества США и Германии с середины 1940-х годов до настоящего времени. Показаны контакты американских разведывательных органов с представителями военных и политических кругов Третьего рейха, реализация планов использования немецких военнопленных в интересах американской армии, участие США в создании вооруженных сил ФРГ. Отмечается, что после объединения Германии немецкие войска вновь появились за пределами ее границ и участвовали в многонациональных маневрах, миссиях ООН и военных операциях. Но суверенитет ФРГ ограничен в силу размещения на ее территории американских военных объектов. Попытки президента Д. Трампа переложить чрезмерное финансовое бремя США в НАТО на европейских участников не совпадают с интересами ФРГ. Поэтому действуя в рамках проекта PESCO, ФРГ совместно с Францией и их ближайшими партнерами стремится обеспечить свою безопасность в рамках ЕС путем создания европейской армии, что, однако, не означает отказа страны от военно-политического сотрудничества с США и участия в Североатлантическом блоке.
\end{abstract}

Ключевые слова: США, Германия, военно-политическое сотрудничество, немецкие военнопленные, НАТО, бундесвер, европейская армия.

Для цитирования: Родович Ю.В. 2020. Военно-политическое сотрудничество США и Германии в 40-е годы XX в. - первые десятилетия XXI в. Via in tempore. История. Политология, 47 (4): 773-782. DOI: 10.18413/2687-0967-2020-47-4-773-782.

\section{Military-political cooperation between the USA and Germany in the forties of the XX century - the first decades of the XXI century}

\author{
Yuri V. Rodovich \\ Tula State Leo Tolstoy Pedagogical University, \\ 125 Lenin Avenue, Tula, 300026, Russia \\ E-mail: tgpu@tula.net
}

\begin{abstract}
The article examines the history of the military-political cooperation between the United States and Germany from the mid-1940s to the present. It shows the contacts of American intelligence agencies with the military and political circles of the Third Reich, the implementation of the plans for the use of German prisoners of war in the interests of the U.S. army, the U.S. participation in the creation of the armed forces of Germany. It is noted that after the unification of Germany, the German troops appeared outside its borders again and participated in the multinational maneuvers, the UN missions and in military operations. But the sovereignty of Germany is limited due to the placement of American military facilities on its territory. President Trump's attempts to shift the excessive financial burden of the US in NATO to the European participants do not coincide with the interests of Germany. Therefore, acting within the framework of the PESCO project, Germany together with France and their closest partners seeks to ensure its security within the EU by creating a European army, which, however, does not mean that the country refuses the military and political cooperation with the United States and the participation in the North Atlantic bloc.
\end{abstract}


Keywords: Germany, USA, NATO, European army.

For citation: Yu.V. Rodovich. 2020. Military-political cooperation between the USA and Germany in the forties of the XX century - the first decades of the XXI century. Via in tempore. History and political science, 47 (4): 773-782 (in Russian). DOI: 10.18413/2687-0967-2020-47-4-773-782.

Проблема военно-политического сотрудничества между США и Германией была и остается одной из наиболее актуальных в исторической науке. Опираясь на новые или малоизученные документы, мемуарную литературу, материалы СМИ, автор настоящей статьи поставил перед собой задачу - проследить эволюцию этого сотрудничества начиная с 40-х гг. XX века и дать оценку его состояния на современном этапе.

Идеи необходимости такого сотрудничества с целью использования «германского фактора» против СССР появились еще в период Второй мировой войны. 4 декабря 1942 г., в разгар Сталинградской битвы, лондонская резидентура внешней разведки СССР узнала о беседе британского посла в США Э. Галифакса с заместителем госсекретаря С. Уэллесом, в ходе которой последний высказал свое опасение, что в случае развала германской военной машины в конце 1942 г, в 1943 или в 1944 гг. Красная армия будет преследовать немецкие войска далеко на западе, что приведет к распространению большевизма, окажет неблагоприятное воздействие на американское общественное мнение и приведет к нарушению «европейской реконструкции» [Очерки истории российской внешней разведки, 1999 , c. 592].

В марте-апреле 1945 г. глава резидентуры американского Управления стратегических служб А. Даллес встречался с руководителем войск СС и сил полиции в Северной Италии обергруппенфюрером СС К. Вольфом. Речь шла о возможности капитуляции перед западными союзниками группировки вермахта в Северной Италии или даже о капитуляции немецких войск на всем западном фронте. По требованию советского руководства эти переговоры прекратились. Однако в конце апреля 1945 г. тайные переговоры союзников с гитлеровской верхушкой были возобновлены. Теперь они велись Гиммлером, Риббентропом, Кальтенбруннером через главу шведского Красного Креста Ф. Бернадотта, контакты с которым были установлены еще в 1943 г. Гиммлер предложил сообщить шведскому правительству о его предложении капитулировать на всем западном фронте [Переписка Председателя Совета Министров СССР..., 2005, с. 577]. В то же время немецкие войска должны были продолжать войну до тех пор, пока фронт западных стран не придет на смену германскому фронту. Союзники были вынуждены информировать советское правительство о переговорах. К военному конфликту с СССР лидеры США и Англии оказались не готовы. Соотношение сил было не в их пользу, о чем они знали из документа Объединенного комитета начальников штабов США, направленном еще в мае 1944 г. государственному секретарю [Великая Отечественная война 1941-1945 годов, 2014, с. 700]. По этой причине и военное руководство США не поддержало предложенный У. Черчиллем план нанесения удара по наступавшей Красной армии силами союзников совместно с Германией (операция «Немыслимое»).

Тем не менее Соединенные Штаты пытались использовать военнопленных немцев в послевоенном противостоянии с Советским Союзом. Во-первых, в июле 1943 г. в американском военном департаменте был создан «отдел специальных проектов», который осенью того же года начал разработку секретной «программы переобучения» немецких военнопленных. Цель проекта - подготовка «лидеров для союзной зоны оккупации», чтобы иметь в Германии государство, которому США смогут доверять. Уже тогда ставка была сделана на немецких пленных как своих будущих союзников в послевоенной Европе. Программа была запущена через год, но успеха не имела.

Во-вторых, 22 апреля 1945 г. начальник штаба сухопутных войск США Дж. Маршалл дал согласие на осуществление англо-американского проекта по изучению архивов 
воинских формирований вермахта, воевавших на восточном фронте. Через месяц было заключено соглашение между разведками Англии и США по изучению немецкого опыта ведения войны против СССР. Это был проект «Хилл» [Рудаков, 2015], который осуществлялся силами немецких пленных офицеров, доставленных в сентябре 1945 г. в лагерь Ритчи, штат Мэриленд. Результаты исследований в рамках проекта предназначались американской армии.

В ноябре 1945 г. после создания нескольких библиографических отчетов под руководством четырех американских и двух британских офицеров началась подготовка исследований по немецкому личному составу и мобилизации, логистике на уровне высшего командования, немецкой фортификации и обороне, немецкой оперативной разведке и т. п. С октября 1945 по апрель 1946 гг. в проекте было задействовано около 200 офицеров, написано 3657 страниц документов для правительств США, Англии и Канады [Рудаков, 2015].

В-третьих, к деятельности США против СССР в первые послевоенные месяцы следует отнести работу «группы Гелена». Через несколько месяцев после падения Третьего рейха генерал-майор Р. Гелен, возглавлявший гитлеровскую разведку на восточном фронте, продолжил свою работу, но уже для нужд американцев. В августе 1945 г. Гелен и несколько его офицеров были отправлены в США, а припрятанные им документы были отправлены в лагерь Ритчи. В дальнейшем некоторые офицеры, участвовавшие в проекте «Хилл», присоединились к работе «группы Гелена». В течение 10 месяцев нахождения в форте Хант, штат Виржиния, группа работала над написанием докладов по истории немецкого опыта ведения разведки против СССР, а к концу своего пребывания в США уже давала консультации американским военным по текущим разведывательным вопросам. Эта группа получила название «Болеро» [Plan for the Inclusion of the Bolero Group in Operation Rusty]. В начале июля 1946 г. группа была возвращена в Германию и включилась в деятельность по воссозданию немецкой разведывательной организации, финансируемой военным департаментом США, а с 1949 г. - ЦРУ, пока в 1956 г. не стала официальным разведывательным органом ФРГ (БНД).

В середине 1947 г. в Вашингтоне и Лондоне приняли окончательное решение о резком обострении конфронтационной политики с СССР. В этих условиях Западная Германия с ее богатыми экономическими и людскими ресурсами превратилась в потенциально союзника. Восстановлению немецкого военно-экономического потенциала способствовало вовлечение Западной Германии в «план Маршалла». Поступающие в нее средства, как отмечал бывший офицер разведки германского рейха, а затем сотрудник западногерманской разведывательной службы БНД Х. Фельфе, использовались для возобновления и развития производства вооружений, строительства и реконструкции транспортной инфраструктуры, мостов, портов, аэродромов, складов боеприпасов и казарм. В 1952 г. военная помощь США Западной Германии в три раза превысила экономическую [Фельфе, 1988, с. 122-123].

После берлинского кризиса 1948-1949 г. ускорился процесс создания западногерманского государства - Федеративной Республики Германия. Уже в ноябре 1949 г. первый канцлер ФРГ К. Аденауэр оценил значимость немецкого военного контингента для Запада. Процессу ремилитаризации ФРГ способствовала война в Корее. В обстановке развернутой на Западе антисоветской кампании 4 июля 1950 г. верховный комиссар в Германии Дж. Макклой заявил, что западные державы будут рассматривать «нападение на Западную Германию как нападение на них самих» [Die auswärtige Politik der Bundesrepublik Deutschland, 1972, S. 845]. Воспользовавшись сложившейся ситуацией, в августе 1950 г. канцлер ФРГ К. Аденауэр высказался за создание из числа добровольцев вооруженных сил численностью 150 тыс. чел. в качестве составной части единой европейской армии [Фельфе, 1988, с. 127].

В том же году появился план французского премьер-министра Франции Р. Плевена о создании Европейского оборонительного сообщества и европейской армии с участием контингентов из ФРГ. 
В октябре 1950 г. в Западной Германии было создано «ведомство Бланка» (будущее министерство обороны ФРГ). Т. Бланк официально отвечал за отношения с оккупационными войсками союзников. На деле под руководством канцлера он вел скрытую подготовку к восстановлению германских вооруженных сил.

В октябре 1950 г. была разработана концепция военной безопасности с учетом не только тогдашнего конфликта между Востоком и Западом, но и опыта Генерального штаба вермахта, осуществившего поход на СССР. Речь шла о общеевропейской «общей обороне от Дарданелл до Скандинавии». Отмечалась необходимость вооружения «современным оружием», то есть атомными бомбами [Bald]. Эту концепцию можно считать важной вехой на пути создания бундесвера.

В марте 1951 г. была организована Федеральная пограничная охрана (BGS). В июле 1953 г. Т. Бланк и генерал А. Хойзингер выезжали в США для ознакомления с организацией и структурой американской армии [Фельфе, 1988, с. 176]. В знак протеста против планируемого перевооружения ушел с поста министра внутренних дел Г. Хайнеман. Западногерманская общественность также выразила свой протест. Однако министры иностранных дел США, Англии и Франции, а также Совет НАТО одобрили соглашение о ремилитаризации ФРГ.

Поскольку «план Плевена» был отвергнут Национальным собранием Франции, США вовлекли Западную Германию непосредственно в Североатлантический блок, добившись подписания 23 октября 1954 г. многосторонних Парижских соглашений. Был отменен оккупационный статус. ФРГ могла создать армию (бундесвер) численностью почти 500 тыс. чел. Но ей запрещалось иметь атомное, химическое и бактериологическое оружие.

Первым послевоенным министром обороны Западной Германии с 1955 по 1956 г. был Т. Бланк. В ноябре 1955 г. первые более 100 добровольцев в бундесвер были приведены к присяге. В начале ноября 1956 г. федеральным правительством было создано семь дивизий, в основном состоявших из бывших офицеров BGS и добровольцев. В дальнейшем бундесвер стал рассматриваться в США в качестве одной из наиболее надежных сил, обеспечивавших «сдерживание» вооруженных сил государств-членов Организации Варшавского Договора.

В 1984 г. ФРГ получила от Западноевропейского союза, членом которого она являлась с 1955 г., согласие на снятие ограничений на военные корабли, ракеты и бомбардировщики. После объединения Германии в 1990 г. немецкие войска вновь появились за пределами германских границ и за пределами собственной обороны НАТО, участвуя не только в многонациональных маневрах или миссиях ООН, но и в активных военных операциях. В 1995 г. самолеты ФРГ совместно с авиацией НАТО наносили авиаудары по позициям сербов во время межэтнического вооруженного конфликта на территории Боснии и Герцеговины, а в 1999 г. впервые со времени Второй мировой войны участвовали в военной акции против Югославии. Бундесвер принял участие в миротворческих миссиях блока в Боснии (с 1995 г.), Косово (с 1999 г.) и Македонии (2001-2003 гг.).

После трагических событий 11 сентября 2001 г. Германия поддержала США в объявленной американским президентом Дж. Бушем-мл. борьбе с международным терроризмом. В ноябре 2001 г. правительство Г. Шредера, получив согласие бундестага, выделило около 3,9 тыс. военнослужащих для операции «Несокрушимая свобода» в Афганистане под руководством США. В 2003 г. германские военные в составе Международных сил содействия безопасности (MCCБ/ISAF) стали участвовать в воссоздании властных структур на местном уровне. Но в 2006 г. представитель Министерства обороны ФРГ признал, что немецкие военные самолеты также использовались на юге Афганистана и поддерживали операции НАТО в этом районе» [Rozoff, 2009]. В 2018 г. немецкие солдаты участвовали в 16 зарубежных миссиях [Басов и др.]. Добившись вывода российских войск с территории Восточной Германии в 1994 г., правительства ФРГ поддерживали планы США о расширении НАТО на восток. 
В 2003 г. руководство ФРГ впервые с момента своего вступления в НАТО выступило против военной акции США в отношении Ирака, хотя с 2006 г. немецкие источники неоднократно сообщали, что Федеральная разведывательная служба (БНД) при правительстве Шредера - Фишера предоставляла американским силам информацию о целях во время бомбардировки Ирака в 2003 г. [Rozoff].

Тем не менее со времени военной интервенции США в Ирак Германия стала занимать более взвешенную позицию по вопросам использования силы вне ее зоны ответственности. В период так называемой «арабской весны» Германия не мешала силам НАТО проводить силовую операцию в отношении Ливии, однако и не планировала использовать в ней бундесвер. Такую же позицию она заняла в период сирийского кризиса. Присоединение к созданной США в сентябре 2014 г. антитеррористической коалиции по борьбе с «Исламским государством» произошло только после совершения ИГ актов террора в Париже в ноябре 2015 г. При этом основным партнером Германии в борьбе с терроризмом в Сирии и Ираке стала Франция, а не США.

Германия при правительствах, возглавляемых А. Меркель, балансировала между организацией НАТО, возглавляемой США, и Европейским союзом, где ФРГ играла ведущую роль. Она поддержала расширение НАТО на Балканах за счет Албании (2009), Хорватии (2009), Черногории (2017), считая это необходимым для правового обоснования своего присутствия в стратегически важном для нее регионе. Вместе с тем германские лидеры выступали против скорейшего включения в состав НАТО Украины и Грузии, чтобы не быть вовлеченными в прямой конфликт с Россией.

Однако суверенитет ФРГ ограничен: на ее территории США разместили свои военные базы. В годы «холодной войны» в Западной Германии, находившейся тогда на первой линии фронта, было 250 американских баз. К 2018 г. оно сократилось до 30 [Świerczyński]. В Германии находятся Европейское командование США в Штутгарте, командование США в Африке в Штутгарте, штаб армии США в Европе в Висбадене, авиабаза Рамштайн ВВС США, больница вооруженных сил США в Ландштуле, учебные заведения в Графенвоере и Хоэнфельсе, войска бригады армии США в Вильсеке (Бавария) и некоторые другие объекты [Wiegold].

История размещения войск США в Германии началась еще в 1945 г. Тогда в Европе находились около 2 млн американских солдат, большая часть которых была дислоцирована на немецкой земле. После окончания войны группировку сократили до 109 тыс. человек. Однако уже к концу 1940-х гг., когда усилилось противостояние между Вашингтоном и Москвой, руководство США приняло решение создать на базе 7-й армии, расквартированной в Германии, штаб американской сухопутной армии в Европе. В дальнейшем численность американского контингента в ФРГ постоянно наращивалась.

Только с 1991 г., после самороспуска Организации Варшавского Договора и распада СССР, США начали сокращать численность своих военнослужащих в Европе, в том числе в Германии. В 2019 г. на территории ФРГ находилось 35,7 тыс. солдат и офицеров. Американских военных в Германии немецкое общество воспринимает весьма болезненно. В июле 2018 г., согласно данным опроса компании You Gov, проведённого по заказу аинформационного агентства DPA, 42 \% немцев выступили за вывод из страны американских войск. За сохранение американского военного присутствия на немецкой земле выступили только 37 \% опрошенных [Fast jeder zweite Deutsche für Abzug der US-Truppen].

США использовали территорию ФРГ для размещения своего ядерного оружия. Осенью 1953 г. в Западной Германии появились артиллерийские орудия с ядерными гранатами. В декабре 1957 г. на сессии Совета НАТО было принято решение о размещении ядерных запасов на территории западноевропейских членов альянса. В мае 1958 г. военные министры блока одобрили план «МС-70» по формированию частей, оснащенных средствами доставки тактического ядерного оружия, в том числе в составе бундесвера. 25 марта 1958 г. бундестаг ФРГ большинством голосов фракции ХДС/ХСС выступил за оснаще- 
ние бундесвера «современным», то есть ракетно-ядерным оружием. В ноябре 1969 г. правительство «малой коалиции» в ФРГ во главе с В. Брандтом подписало Договор о нераспространении ядерного оружия. Однако генералы бундесвера и некоторые влиятельные политические круги ФРГ не оставили надежды на получение доступа к ядерному оружию в той или иной форме [Klein, S. 259-260].

12 декабря 1979 г. было принято т. н. «двойное решение» НАТО: вести американосоветские переговоры об ограничении ракет средней дальности двух стран, а в случае их неудачи «довооружаться», т. е. размещать ракеты США в Западной Европе. После принятия западногерманским бундестагом 22 ноября 1983 г. решения о готовности принять на территории ФРГ американские ядерные ракеты СССР покинул стол переговоров. США начали размещение в Западной Европе, в том числе в ФРГ, ядерных ракет средней дальности, что вызвало принятие Советским Союзом ответных мер. Ситуация в Европе и мире в целом резко обострилась.

Лишь в условиях позитивных перемен в международной обстановке во второй половине 1980-х гг. после длительных проволочек руководство ФРГ стало содействовать заключению между США и СССР Договора о ликвидации ракет средней и меньшей дальности. Договор был подписан 8 декабря 1987 г.

В соответствии с «Договором об окончательном урегулировании в отношении Германии», подписанным ФРГ, ГДР, СССР, США, Великобританией и Францией 12 сентября 1990 г., объединенная Германия отказывалась от производства, обладания и распоряжения ядерным, биологическим и химическим оружием. В сентябре 1996 г. К. Кинкель, министр иностранных дел ФРГ в правительстве Г. Коля, подписал Договор о всеобъемлющем запрещении ядерных испытаний. Позже он подверг критике США за отказ от ратификации этого документа [Егоров, с. 65]. Позиция Вашингтона по этому вопросу в ноябре 1999 г. подверглась критике и со стороны главы МИД ФРГ Й. Фишера в правительстве Г. Шредера. После выступления президента США Б. Обамы в Праге 5 апреля 2009 г. с призывом к созданию безъядерного мира в коалиционный договор ХДС/ХСС и СвДП от 26 октября 2009 г. было включено положение относительно вывода американского ядерного оружия из Германии [Wachstum. Bildung. Zusammenhal, S. 120]. В марте 2010 г. бундестаг предложил правительству ФРГ убедить союзников по НАТО в необходимости вывести оставшиеся ядерное оружие США с территории Германии [Abrüstung]. Однако в коалиционном договоре между партиями ХДС/ХСС и СДПГ от 16 декабря 2013 г. предлагалось сохранить ядерное оружие в качестве «инструмента сдерживания» в стратегической концепции HATO, а Германия должна был сохранять «интерес к стратегическим дискуссиям и процессам планирования». Партнеры по коалиции связали вывод с территории страны тактического ядерного оружия с успехом переговоров между США и Россией по разоружению [Deutschlands Zukunft gestalten Koalitionsvertrag]. Изменение позиции германской правящей элиты было обусловлено давлением на нее со стороны Вашингтона, следованием «натовской дисциплине», ухудшением отношений с Россией.

США по-прежнему сохраняли в Европе свое тактическое ядерное оружие и даже запланировали его модернизацию. Американские бомбы размещены на базах ВВС США в Брюггене, Бюхеле, Норфенихе, Меммингене, Рамштайне, Шпандалеме [Ярошинская]. Самолеты «Торнадо» германских ВВС стали проводить тренировки, используя муляжи доставленных на военную базу Бюхель 20 американских ядерных бомб. Хотя в заключенном между ХДС/ХСС и СДПГ коалиционном договоре от 12 марта 2018 г. подчеркивалось, что целью политики правительства ФРГ «является мир, свободный от ядерного оружия», подтверждалась позиция партнеров по коалиции, которую они занимали в 2013 г. [Ein neuer Aufbruch für Europa].

Солдаты бундесвера проходили подготовку на военных объектах США, регулярно участвовали в совместных учениях и работали в военных штабах как в США, так и в Германии. С осени 2014 г. пост начальника штаба $(\mathrm{CoS})$ в штаб-квартире американской армии 
в Европе (USAREUR), базирующейся в Висбадене, занимал немецкий бригадный генерал, который на это время являлся военнослужащим армии США. Между двумя государствами развивается сотрудничество в области оборонных технологий. Немецкое представительство по оборонным связям в Соединенных Штатах и ряд офицеров связи в ключевых американских офисах - очевидные свидетельства такого рода сотрудничества. В Ньюпорте, Уэльсе (2014 г.) и в Варшаве (2016 г.) страны - члены НАТО приняли меры по перестраховке восточных союзников. Германия взяла на себя руководство многонациональным батальоном в Литве. Инициатива по усилению и обучению трансатлантических возможностей (ТАСЕТ) способствует укреплению военного потенциала и координации проектов учений в Восточной Европе [Deutschland und USA].

Министр обороны ФРГ У. фон дер Ляйен (ныне - председатель Еврокомиссии Ю.Р.) приветствовала наращивание военного присутствия США в ФРГ как зримый знак жизнеспособности трансатлантических отношений [Басов и др.]. Курс на развитие германо-американского военно-политического сотрудничества продолжает и новый министр обороны (с 17 июля 2019 г.) А. Крамп-Карренбауэр.

В «Белой книге бундесвера» 2016 г., определяющей основные направления военнополитической стратегии ФРГ на ближайшие годы, как и в «Белой книге» 2006 г., подчеркивается стремление Германии быть надежным партнером в ЕС и НАТО. В то же время в новом документе Германия фигурирует в качестве центрального действующего актора в Европе. Отмечается ее готовность брать на себя больше ответственности в урегулировании и предотвращении конфликтов [Weissbuch].

После окончания «холодной войны» и появления европейской «опоры» НАТО главным для Вашингтона стало не допустить дублирования функций и автономизации европейского военного блока, а сделать его гармоничной частью НАТО, усиливая вклад ЕС в эту организацию. По мнению же Берлина, усиление европейского военного потенциала должно было создавать сбалансированные трансатлантические отношения, забирая часть нагрузки с США и обеспечивать готовность к самостоятельным действиям в тех случаях, когда НАТО откажется от участия в каких-либо операциях, а европейцы сочтут это необходимым [Гаевой, 2015, с. 17].

С приходом на пост президента Соединенных Штатов Америки в 2017 г. Д. Трампа прослеживается стремление последнего переложить чрезмерное финансовое бремя США в НАТО на европейских участников, добиться увеличения их расходов за каждый дополнительный батальон, переброшенный на континент. Но такие намерения не совпадают с интересами ФРГ. Она стремится активизировать действия в рамках «Постоянного структурированного сотрудничества» (PESCO), оформленного 13 ноября 2017 г. на базе ЕС, без участия США и Великобритании. Речь шла о повышении оперативной совместимости и координации действий вооруженных сил стран-участниц, наращивании совместных группировок под командованием штабных структур ЕС, углублении кооперации в военнопромышленной сфере, в том числе робототехники, кооперации в борьбе с киберугрозами. Страны-участницы согласились довести расходы на оборону до $2 \%$ от ВВП [Europaische Union-Staaten melden PESCO].

Реализация проекта PESCO позволяет ФРГ совместно с Францией и их ближайшими партнерами создать европейскую армию и осуществлять военно-политические акции за пределами НАТО, производить продукцию военного назначения без США и Великобритании, а также обеспечить переподчинение части германских военных контингентов Евросоюзу.

Тем не менее безопасность ФРГ еще относительно продолжительное время не будет рассматриваться вне военно-политического сотрудничества Германии с США и участия в Североатлантическом блоке, что обусловлено позицией немецкой политической и военной элиты, руководства НАТО и ЕС, размещением на германской территории американских военных объектов и значительной интеграцией бундесвера в структуры НАТО. 


\section{Список литературы}

1. Басов Ф., Васильев В., Кокеев А., Хорольская М. 2018. Немецкое представление о безопасности. Международная жизнь, 10. URL: https://interaffairs.ru/jauthor/material/2089 (дата обращения: 07.07.2019).

2. Великая Отечественная война 1941-1945 годов. В 12 т. Т. 9. Союзники СССР по антигитлеровской коалиции. 2014. М., Кучково поле, 864.

3. Гаевой Г.Е. 2015. Американо-германские отношения: 1990-2013 гг.: автореферат дис. ... канд.исторических наук. Томск, 23.

4. Егоров А.И. 2013. Позиция Германии по вопросу нераспространения оружия массового уничтожения и ядерных материалов (1990-е - начало 2000-х гг.). Вестник Томского государственного университета, 367: 64-68.

5. Очерки истории российской внешней разведки. Гл. ред. В.И. Трубников. В 6 т. Т. 4. 1941-1945 гг. 1999. М., Международные отношения, 696.

6. Переписка Председателя Совета Министров СССР с президентами США и премьерминистрами Великобритании во время Великой Отечественной войны, 1941-1945 гг.: переписка с У. Черчиллем и К. Эттли (июль 1941 г. - ноябрь 1945 г.), переписка с Ф. Рузвельтом и Г. Трумэном (август 1941 г. - декабрь 1945 г.). Министерство иностранных дел РФ. 2005. М.: Воскресенье, 647.

7. Рудаков В. Роль и место США в подрыве послевоенного мирового порядка. 12.03.2015. URL: http://www.old.ural-eurasia.ru/mnenie/rol-i-mesto-ssha-v-podryve-poslevoennogo-mirovogoporyadka/https://russian.rt.com/world/article/531459-ssha-voennye-germaniya (дата обращения: 07.07.2019).

8. Фельфе Х. 1988. Мемуары разведчика. Пер. с нем. М., Политиздат, 319.

9. Ярошинская А. Новые атомные бомбы уже в Германии. 23.09.2015. URL: http://www .rosbalt.ru/main/2015/09/23/1443663.html (дата обращения: 10.06.2019).

10. Abrüstung. Bundestag fordert Abzug von US-Atomwaffen. 26.03.2010. URL: https://www .zeit.de/politik/deutschland/2010-03/bundestag-atomwaffen-abruestung (accessed: 10.06.2019).

11. Bald D. Die Politik der Wiederbewaffnung. 01.05.2015. URL:https://www.bpb.de/politik/ grundfragen /deutsche- verteidigungspolitik /199276/ wiederbewaffnung (accessed: 11.06.2019).

12. Deutschlands Zukunft gestalten Koalitionsvertrag zwischen CDU, CSU und SPD. 18. Legislaturperiode. 2013. URL: https://www.bundesregierung. de/Content/DE/ _Anlagen/2013/2013-12-17koalitionsvertrag.pdf?_blob=publicationFile (accessed: 12.06.2019).

13. Deutschland und USA: bilaterale Beziehungen. 27.05.2019. URL: https://www.auswaertigesamt.de/de/aussenpolitik/laender/usa-node/bilateral/204568 (accessed: 10.06.2019). tik, 989.

14. Die auswärtige Politik der Bundesrepublik Deutschland. 1972. Koln, Wissenschaft und Poli-

15. Fast jeder zweite Deutsche für Abzug der US-Truppen. 11.07.2018. URL: https://www.welt.de/newsticker/dpa_nt/infoline_nt/brennpunkte_nt/article179150408/Fast-jeder-zweiteDeutsche-fuer-Abzug-der-US-Truppen.html (accessed: 18.07.2019).

16. Plan for the Inclusion of the Bolero Group in Operation Rusty. July 2, 1946. URL: https: //nsarchive2.gwu.edu/NSAEBB/NSAEBB146/doc17.pdf (accessed: 11.07.2019).

17. Ein neuer Aufbruch für Europa. Eine neue Dynamik für Deutschland. Ein neuer Zusammenhalt für unser Land. Koalitionsvertrag zwischen CDU, CSU und SPD. 19. Legislaturperiode. Berlin, den 12. März 2018. URL: https://www.bundesregierung. de/Content/DE/_Anlagen/2018/03/2018-03-14(accessed: 16.07.2019).

18. Europaische Union-Staaten melden PESCO (Permanent Structured Cooperation) - Teilnahme. 13.11.2017. URL: https://www.bmvg.de/de/aktuelles/eu-staaten-melden-pesco-teilnahme-19568 (accessed: 16.07.2019).

19. Klein P. 1970. Aktuelle Fragen der Rüstungsbeschränkung und Abrüstung. Deutsche Aussenpolitik. 2: 259-260.

20. Rozoff R. Deutschland: Die erste nach dem Kalten Krieg entstandene neue militärische Großmacht (Teil 3). 28.07. 2009. URL: https://www.hintergrund.de/politik/inland/deutschland-die-erstenach-dem-kalten-krieg-entstandene-neue-militaerische-grossmacht-teil-3(accessed: 13.07.2019). 
21. Świerczyński M. Amerykańskie bazy z Niemiec do Polski? Nie tak szybko. 01.07.2018. URL: $\quad$ https://www.polityka.pl/tygodnikpolityka/swiat/1754480,1, amerykanskie-bazy-z-niemiec-dopolski-nie-tak-szybko.read(accessed: 11.07.2019).

22. Wachstum. Bildung. Zusammenhalt. Koalitionsvertrag zwischen CDU, CSU und FDP. 17. Legislaturperiode. 2009. Berlin, Friedrich-Ebert-Stiftung, 132.

23. Weissbuch. Zur Sicherheitspolitik und zur Zukunft der Bundeswehr. 2016. URL: https:// www.bmvg.de/resource/blob/13708/015be272f8c0098f1537a491676bfc31/weissbuch2016-barrierefreidata.pdf (accessed: 11.01.2020).

24. Wiegold T. US-Truppen raus aus Deutschland? Ein Blick auf die Fakten. 30.06.2018. URL: https://augengeradeaus.net/2018/06/us-truppen-raus-aus-deutschland-ein-blick-auf-die-fakten/ (accessed: 16.07.2019).

\section{References}

1. Basov F., Vasil`ev V., Kokeev A., Xorol`skaya M. 2018. Nemeczkoe predstavlenie o bezopasnosti [German vision of security]. Mezhdunarodnaya zhizn, 10. URL: https://interaffairs.ru/jauthor/material/2089 (accessed: 07.07. 2019) (in Russian).

2. Velikaya Otechestvennaya vojna 1941-1945 godov [The Great Patriotic War of 1941-1945.]. V 12 t. T. 9. Soyuzniki SSSR po antigitlerovskoj koalicii [Allies of the USSR in the anti-Hitler coalition]. 2014. M., Kuchkovo pole, 864 (in Russian).

3. Gaevoj G.E. 2015. Amerikano-germanskie otnosheniya: 1990-2013 gg. [American-German Relations: 1990-2013]: avtoreferat dis. ... kand. istoricheskix nauk. Tomsk, 23 (in Russian).

4. Egorov A.I. 2013. Poziciya Germanii po voprosu nerasprostraneniya oruzhiya massovogo unichtozheniya i yaderny`x materialov (1990-e - nachalo 2000-x gg.) [Germany's position on the nonproliferation of weapons of mass destruction and nuclear materials (1990s - early 2000s)]. Vestnik Tomskogo gosudarstvennogo universiteta, 367: 64-68 (in Russian).

5. Ocherki istorii rossijskoj vneshnej razvedki [Essays on the history of Russian foreign intelligence] / Gl. red. V.I. Trubnikov. V 6 t. T. 4. 1941-1945 gg. 1999. M., Mezhdunarodny`e otnosheniya, 696 (in Russian).

6. Perepiska Predsedatelya Soveta Ministrov SSSR s prezidentami SShA i prem`er-ministrami Velikobritanii vo vremya Velikoj Otechestvennoj vojny', 1941-1945 gg.: perepiska s U. Cherchillem i K. E`ttli (iyul 1941 g. - noyabr` 1945 g.), perepiska s F. Ruzvel`tom i G. Trume`nom (avgust 1941 g. dekabr` 1945 g.) [Correspondence of the Chairman of the Council of Ministers of the USSR with the Presidents of the United States and Prime Ministers of Great Britain during the Great Patriotic War, 1941-1945: correspondence with W. Churchill and C. Attlee (July 1941 - November 1945), correspondence with F. Roosevelt and H. Truman (August 1941 - December 1945)]. Ministerstvo inostranny`x del RF. 2005. M., Voskresen`e, 647 (in Russian).

7. Rudakov V. Rol' i mesto SShA v podry`ve poslevoennogo mirovogo poryadka [Rolleu and the USA's place in the underwear of the post-war world order]. 12.03.2015. URL: http://www.old.uraleurasia.ru/mnenie/rol-i-mesto-ssha-v-podryve-poslevoennogo-mirovogoporyadka/https://russian.rt.com/world/article/531459-ssha-voennye-germaniya (accessed: 07.07. 2019). Russian).

8. Fel`fe X. 1988. Memuary` razvedchika [Scout Memoirs]. Per. s nem. M., Politizdat, 319 (in

9. Yaroshinskaya A. Novy`e atomny`e bomby` uzhe v Germanii [New atomic bomb already in Germany]. 23.09.2015. URL: http://www.rosbalt.ru/main/2015/09/23/1443663.html (data obrashheniya: 10.06. 2019).

10. Abrüstung. Bundestag fordert Abzug von US-Atomwaffen. 26.03.2010. URL: https://www .zeit.de/politik/deutschland/2010-03/bundestag-atomwaffen-abruestung (accessed: 10.06.2019).

11. Bald D. Die Politik der Wiederbewaffnung. 01.05.2015. URL:https://www.bpb.de/politik/ grundfragen /deutsche- verteidigungspolitik /199276/ wiederbewaffnung (accessed: 11.06.2019).

12. Deutschlands Zukunft gestalten Koalitionsvertrag zwischen CDU, CSU und SPD. 18. Legislaturperiode. 2013. URL: https://www.bundesregierung. de/Content/DE/ _Anlagen/2013/2013-12-17koalitionsvertrag.pdf?_blob=publicationFile (accessed: 12.06.2019).

13. Deutschland und USA: bilaterale Beziehungen. 27.05.2019. URL: https://www.auswaertigesamt.de/de/aussenpolitik/laender/usa-node/bilateral/204568 (accessed: 10.06.2019). 

tik, 989.

14. Die auswärtige Politik der Bundesrepublik Deutschland. 1972. Koln, Wissenschaft und Poli-

15. Fast jeder zweite Deutsche für Abzug der US-Truppen. 11.07.2018. URL: https://www.welt.de/newsticker/dpa_nt/infoline_nt/brennpunkte_nt/article179150408/Fast-jeder-zweiteDeutsche-fuer-Abzug-der-US-Truppen.html (accessed: 18.07.2019).

16. Plan for the Inclusion of the Bolero Group in Operation Rusty. July 2, 1946. URL: https: //nsarchive2.gwu.edu/NSAEBB/NSAEBB146/doc17.pdf (accessed: 11.07.2019).

17. Ein neuer Aufbruch für Europa. Eine neue Dynamik für Deutschland. Ein neuer Zusammenhalt für unser Land. Koalitionsvertrag zwischen CDU, CSU und SPD. 19. Legislaturperiode. Berlin, den 12. März 2018. URL: https://www.bundesregierung. de/Content/DE/_Anlagen/2018/03/2018-03-14(accessed: 16.07.2019).

18. Europaische Union-Staaten melden PESCO (Permanent Structured Cooperation) - Teilnahme. 13.11.2017. URL: https://www.bmvg.de/de/aktuelles/eu-staaten-melden-pesco-teilnahme-19568 (accessed: 16.07.2019).

19. Klein P. 1970. Aktuelle Fragen der Rüstungsbeschränkung und Abrüstung. Deutsche Aussenpolitik. 2: 259-260.

20. Rozoff R. Deutschland: Die erste nach dem Kalten Krieg entstandene neue militärische Großmacht (Teil 3). 28.07. 2009. URL: https://www.hintergrund.de/politik/inland/deutschland-die-erstenach-dem-kalten-krieg-entstandene-neue-militaerische-grossmacht-teil-3(accessed: 13.07.2019).

21. Świerczyński M. Amerykańskie bazy z Niemiec do Polski? Nie tak szybko. 01.07.2018. URL: https://www.polityka.pl/tygodnikpolityka/swiat/1754480,1,amerykanskie-bazy-z-niemiec-dopolski-nie-tak-szybko.read(accessed: 11.07.2019).

22. Wachstum. Bildung. Zusammenhalt. Koalitionsvertrag zwischen CDU, CSU und FDP. 17. Legislaturperiode. 2009. Berlin, Friedrich-Ebert-Stiftung, 132.

23. Weissbuch. Zur Sicherheitspolitik und zur Zukunft der Bundeswehr. 2016. URL: https:// www.bmvg.de/resource/blob/13708/015be272f8c0098f1537a491676bfc31/weissbuch2016-barrierefreidata.pdf (accessed: 11.01.2020).

24. Wiegold T. US-Truppen raus aus Deutschland? Ein Blick auf die Fakten. 30.06.2018. URL: https://augengeradeaus.net/2018/06/us-truppen-raus-aus-deutschland-ein-blick-auf-die-fakten/ (accessed: 16.07.2019).

\section{ИНФОРМАЦИЯ ОБ АВТОРЕ}

Родович Юрий Владиславович, доктор исторических наук, профессор кафедры истории и археологии Тульского государственного педагогического университета им. Л.Н. Толстого, г. Тула, Россия

\section{INFORMATION ABOUT THE AUTHOR}

Yuri V. Rodovich, Doctor of Historical Sciences, Professor of the Department of History and Archeology, Tula State Pedagogical University named after L.N. Tolstoy, Tula, Russia 